\title{
EFEKTIVITAS PENATALAKSANAAN NYERI HAID DENGAN TEKNIK SENAM HAID DAN KONSUMSI KUNYIT ASAM PADA MAHASISWI STIKES KUSUMA HUSADA SURAKARTA TAHUN 2018
}

\begin{abstract}
The Effectiveness of Menstrual Pain Management Using Menstrual Exercises and Consumption of Turmeric Acid in Stikes Kusuma Husada Surakarta
\end{abstract} StudentsYear 2018

\author{
Wahyu Dwi Agussafutri, Christiani Bumi Pangesti \\ STIKes Kusuma Husada Surakarta \\ (wahyudazafa@gmail.com)
}

\begin{abstract}
ABSTRAK
Latar Belakang : Dismenore menyebabkan wanita-wanita muda pergi ke dokter untuk konsultasi dan pengobatan karena gangguan ini sifatnya subjektif, berat, atau intensitasnya sukar dinilai. Banyak wanita terpaksa harus berbaring karena terlalu menderita saat dismenore sehingga terkadang tidak mampu mengerjakan apapun, ada beberapa wanita sampai pingsan, merasa sangat mual bahkan ada yang sampai muntah. Secara garis besar cara untuk mengatasi nyeri ada dua, yaitu farmakologi dan non farmakologi. Secara farmakologi dengan sedative dan analgetik sedangkan secara non farmakologi dengan tindakan fisik (masase, vibrator, kompres hangat dan dingin, olah raga ringan seperti jalan kaki, senam dan bersepeda, dan tidur terlentang dengan kaki/lutut diganjal bantal) dan tindakan kognitif behavior (relaksasi dan distraksi). Produk herbal atau fitofarmaka juga bisa menjadi terapi alternatif untuk mengurangi nyeri haid pada beberapa orang. Senam haid dan konsumsi kunyit asam adalah beberapa contoh terapi untuk mengurangi nyeri haid.

Tujuan Penelitian : Penelitian ini bertujuan untuk mengetahui perbedaan intensitas nyeri haid antara penatalaksanaan senam haid dan komsumsi kunyit asam.

Metode : Penelitian ini adalah analitik eksperimental. Kelompok eksperimen dalam penelitian ini ada 2 kelompok yang diberikan intervensi berbeda, yaitu kelompok yang melakukan senam haid dan kelompok yang mengkonsusmi kunyit asam. Metode analisis data yang digunakan adalah Mann Whitney

Hasil : hasil uji statistik menggunakan Wilcoxon test didapatkan bahwa sebelum dan sesudah senam haid $\mathrm{p}=0,001$, sebelum dan sesudah konsumsi kunyit asam $\mathrm{p}=0,001$. Kedua intervensi tersebut sama-sama efektif dalam mengurangi nyeri haid. Hal ini dapat dilihat dari uji statistik Mann Whitney didapatkan $\mathrm{p}=0,405$.

Simpulan: Senam haid $(\mathrm{p}<0,001)$ dan konsumsi kunyit asam $(\mathrm{p}<0,001)$ menunjukkan efektivitas yang secara statistik signifikan untuk mengurangi intensitas nyeri haid.
\end{abstract}

Kata kunci: nyeri haid, senam haid, konsumsi kunyit asam 


\begin{abstract}
Background: Dysmenorrhea causes young women to go to the doctor for consultation and treatment because this disorder is subjective, severe, or the intensity is difficult to assess. Many women are forced to lie down because they suffer too much during dysmenorrhea so that sometimes they are unable to do anything, there are some women who pass out, feel very nauseous and even vomit. Broadly speaking, there are two ways to deal with pain, namely pharmacology and non-pharmacology. Pharmacologically with sedatives and analgesics while non-pharmacologically with physical actions (massage, vibrator, warm and cold compresses, mild exercise such as walking, gymnastics and cycling, and sleeping supine with feet / knees propped up by pillows) and cognitive behavioral actions (relaxation and distraction). Herbal products or fitofarmaka can also be an alternative therapy to reduce menstrual pain in some people. Menstrual exercise and consumption of sour turmeric are some examples of therapy to reduce menstrual pain.
\end{abstract}

The Aim : This study aims to determine the difference in menstrual pain intensity between the management of menstrual exercise and the consumption of turmeric acid.

Method:This study is analytic experimental, which were 2 groups that would given different interventions, namely the group that did menstrual exercise and the group that consumed turmeric acid. The data analysis method used was Mann Whitney

Result: the results of statistical tests using the Wilcoxon test found that before and after menstrual exercise $p=0.001$, before and after consumption of turmeric acid $p=0.001$. Both of these interventions are equally effective in reducing menstrual pain. This can be seen from the Mann Whitney statistical test obtained $p=0.405$ Conclusion: Menstrual exercise $(p<0.001)$ and consumption of turmeric acid ( $p$ $<0.001)$ showed effectiveness that was statistically significant for reducing the intensity of menstrual pain

Keywords: menstrual pain, menstrual exercise, consumption of turmeric acid

\title{
PENDAHULUAN
}

Menstruasi merupakan tanda bahwa siklus masa subur telah dimulai dan merupakan salah satu ciri kedewasaan perempuan yang ditandai dengan perdarahan secara periodik dari rahim serta meluruhnya selaput endometrium.(Proverawati dan Maisaroh, 2009; Saktiyono, 2006 ). Pada saat menstruasi wanita terkadang mengalami nyeri. Sifat dan tingkat rasa nyeri bervariasi, mulai dari yang ringan hingga yang berat. Kondisi tersebut dinamakan dismenore, yaitu keadaan nyeri yang hebat dan dapat mengganggu aktivitas sehari- hari (Kusmiran, 2011)..

Dismenore menyebabkan wanita-wanita muda pergi ke dokter untuk konsultasi dan pengobatan karena gangguan ini sifatnya subjektif, berat, atau 
intensitasnya sukar dinilai (Wiknjosastro, 2008). Banyak wanita terpaksa harus berbaring karena terlalu menderita saat dismenore sehingga terkadang tidak mampu mengerjakan apapun, ada beberapa wanita sampai pingsan, merasa sangat mual bahkan ada yang sampai muntah (Arkhan, 2010).

Di Amerika Serikat, prevalensi dismenorea diperkirakan 45-90\% (Anurogo dan Wulandari, 2011). Di Meksiko angka kejadian dismenore mencapai $64 \%$, Italia 68\%, Jordania 55,8\%, Turki 84,9\%, dan Malaysia 74,5\% (Ortiz, 2010; Ping dan Ming, 2010; Al-jefout et al., 2014; Seven dan Eski 2014; Zannoni et al., 2014). Di Indonesia, tidak ada angka pasti prevalensi penderita dismenore. Penelitian yang dilakukan oleh Novia dan Puspitasari (2008) di desa Banjar Kematren dengan 100 responden wanita usia subur (15-30 tahun), ditemukan 71\% responden mengalami dismenore primer.

Secara garis besar cara untuk mengatasi nyeri ada dua, yaitu farmakologi dan non farmakologi. Secara farmakologi dengan sedative dan analgetik sedangkan secara non farmakologi dengan tindakan fisik (masase, vibrator, kompres hangat dan dingin, olah raga ringan seperti jalan kaki, senam dan bersepeda, dan tidur terlentang dengan kaki/lutut diganjal bantal) dan tindakan kognitif behavior (relaksasi dan distraksi) (Wijayakusuma, 2008; Alphatino, 2009).

Beberapa wanita berkurang nyerinya melalui olah raga misalnya senam. Senam tidak hanya mengurangi stres tapi juga meningkatkan produksi endorphin otak yang merupakan penawar sakit alami tubuh. Tidak ada pembatasan aktivitas selama haid (Arifin, 2010). Salah satu produk herbal yang biasa dikonsumsi dan dikenal oleh masyarakat untuk mengurangi nyeri adalah kunyit asam. Curcumine akan bekerja menghambat reaksi cyclooxygenase (COX-2) sehingga menghambat atau mengurangi terjadinya inflamasi dan akan mengurangi kontraksi uterus (Wieser et al, 2007). Penelitian yang dilakukan oleh Anindita (2010) dan Marlina (2012) menunjukkan bahwa konsumsi kunyit asam dapat menurunkan nyeri haid.

Pada studi pendahuluan yang peneliti lakukan pada mahasiswi di STIKes Kusuma Husada mengenai dismenorea, dari 89 mahasiswi 64 mahasiswi (72\%) mengalami dismenore ketika haid Menurut mereka, dismenorea sangat mengganggu konsentrasi belajar saat proses belajar mengajar.

Berdasarkan latar belakang di atas, peneliti tertarik untuk melakukan penelitian efektivitas penatalaksanaan nyeri haid dengan teknik senam haid dan konsumsi kunyit asam pada mahasiswi STIKes Kusuma Husada Surakarta.

Tujuan dari penelitian ini adalah untuk mengetahui efektivitas penatalaksanaan nyeri haid dengan teknik senam haid dan konsumsi kunyit asam pada mahasiswi STIKes Kusuma Husada Surakarta.

Dismenore adalah menstruasi yang sangat nyeri. Banyak wanita yang merasakan ketidaknyamanan pada awitan menstruasi, tetapi tingkat ketidaknyamanan dismenore jauh lebih tinggi, dengan nyeri yang sering kali dirasakan di punggung bawah dan menjalar ke bawah hingga ke bagian atas tungkai (Andrews, 2010). Sakit saat menstruasi akibat dismenore ini sampai dapat mengganggu aktivitas sehari-hari (Manuaba, 2012).

Beberapa ahli seperti Wiknjosastro (2008) dan Baziad (2008) cenderung mengklasifikasikan dismenore menjadi 2 macam yaitu dismenorea primer dan 
dismenorea sekunder, mengingat dismenorea tipe membranous jarang sekali dijumpai.

Sifat rasa nyeri pada dismenorea primer biasanya terbatas pada perut bawah, tetapi dapat menyebar ke daerah pinggang dan paha (Wiknjosastro, 2006). Lokasi nyeri dapat terjadi di daerah suprapubik, terasa tajam, menusuk, terasa diremas atau sangat sakit. Selain rasa nyeri, dapat disertai dengan gejala sistematik dan gangguan emosional (Mitayani, 2009)..

Gejala lain yang terkait dengan dismenore primer dapat berupa mual/muntah, pucat/lemas, sakit kepala/migraine, gangguan usus dan iritabilitas kandung kemih (Andrews, 2010).

Faktor yang menyebabkan dismenore antara lain adalah faktor kejiwaan (psikologis), konstitusi, obstruksi kanalis servikalis, endokrin, dan alergi.

Peningkatan kadar prostaglandin yang berlebihan akan menyebabkan dismenorea yang dapat disertai kram pada perut, sakit punggung, mual, muntah, diare, sakit kepala (Perry dan Bobak, 2004)

Latihan-latihan olahraga yang ringan sangat dianjurkan untuk mengurangi dismenore. Olahraga/senam merupakan salah satu teknik yang dapat digunakan untuk mengurangi nyeri karena saat melakukan olahraga/senam tubuh akan menghasilkan endorphin. Endorphin dihasilkan di otak dan susunan syaraf tulang belakang. Hormon ini dapat berfungsi sebagai obat penenang alami yang diproduksi otak sehingga menimbulkan rasa nyaman (Puji, 2010).

Kandungan bahan alami minuman kunyit asam bisa mengurangi keluhan dismenore primer. Curcumine dan anthocyanin akan bekerja dalam menghambat rekasi cyclooxygenase (COX) sehingga menghambat atau mengurangi terjadinya inflamasi (Wieser, et al., 2007; Hoppe, 2010), mengurangi atau bahkan menghambat kontraksi uterus (Thaina, et al., 2009). Mekanisme penghambatan kontraksi uterus melalui curcumine adalah dengan mengurangi influks ion kalsium $(\mathrm{Ca} 2+)$ ke dalam kanal kalsium pada sel-sel epitel uterus (Thaina, et al., 2009).

\section{METODE PENELITIAN}

Penelitian ini dilakukan dilakukan di STIKes Kusuma Husada Surakarta, jalan Jaya Wijaya No. 11 Kadipiro Surakarta. Waktu penelitian selama kurang lebih 6 bulan yaitu pada bulan Februari sampai Juli 2018.

Jenis penelitian ini adalah analitik eksperimental. Kelompok eksperimen dalam penelitian ini ada 2 kelompok yang diberikan intervensi berbeda, yaitu kelompok yang melakukan senam haid dan kelompok yang mengkonsusmi kunyit asam, sebelumnya dilakukan pre test dan post test intensitas nyeri haid.

Populasi sasaran dalam penelitian ini adalah mahasiswi yang mengalami nyeri haid dan populasi sumbernya adalah mahasiswi Stikes Kusuma Husada Surakarta yang berjumlah 247 siswi. Dengan menggunakan "rule of thumb", ukuran sampel sebesar 30 subjek penelitian. Kriteria inklusi subjek penelitian adalah mengalami nyeri haid, umur subjek penelitian antara 17-20 tahun, belum menikah, dan bersedia menjadi subjek penelitian dalam penelitian ini. Sedangkan 
kriteria eksklusi adalah terdapat kelainan pelvic seperti endometriosis, mioma uteri, stenosis serviks dan tidak bersedia menjadi subjek dalam penelitian ini.

Variabel dependen dalam penelitian ini adalah intensitas nyeri haid dan variabel independennya senam haid dan konsumsi kunyit asam. Variabel penelitian terukur dalam skala kategorik. Instrumen yang digunakan dalam penelitian ini adalah check list intensitas nyeri berupa skala nyeri Bourbanis yaitu skala nyeri yang mempunyai rentang angka 0-10 dengan ketentuan: 0 tidak ada nyeri, 1-3 nyeri ringan, 4-6 nyeri sedang, 7-9 nyeri berat dan 10 adalah nyeri sangat berat.

Metode pengumpulan data menggunakan checklist observasi yang diberikan kepada subjek penelitian mengenai skala nyeri yang dirasakan sebelum dan sesudah melakukan senam haid.

Analisis univariat dalam penelitian ini, karakteristik subjek penelitian dideskripsikan dalam $\mathrm{n}$ dan persentase. Analisis bivariat diuji dengan statistik SPSS versi 17.0, karena variabel terukur dalam skala ordinal, uji statistik yang digunakan adalah Wilcoxson.

\section{HASIL DAN PEMBAHASAN}

Tabel 1 Intensitas nyeri haid sebelum dan sesudah senam haid

\begin{tabular}{lccccc}
\hline \multirow{2}{*}{$\begin{array}{l}\text { Intensitas } \\
\text { nyeri haid }\end{array}$} & \multicolumn{4}{c}{ Sebelum } & \multicolumn{2}{c}{ Sesudah } & Asymp \\
\cline { 2 - 5 } & $\mathrm{n}$ & \multicolumn{1}{c}{. Sig } \\
\cline { 2 - 5 } Tidak nyeri & 0 & 0 & 7 & 23,3 & 0,001 \\
Nyeri ringan & 8 & 26,7 & 18 & 60 & \\
$\begin{array}{l}\text { Nyeri } \\
\text { sedang }\end{array}$ & 18 & 60 & 4 & 13,3 & \\
$\begin{array}{l}\text { Nyeri berat } \\
\text { Nyeri sangat }\end{array}$ & 2 & 6,7 & 1 & 3,3 & \\
berat & 2 & 6,7 & 0 & 0 & \\
Total & 30 & 100 & 30 & 100 & \\
\hline
\end{tabular}

Dari tabel di atas dapat dilihat bahwa sebelum melakukan senam haid, sebagian besar subyek penelitian mengalami nyeri sedang (60\%) dan setelah melakukan senam haid, sebagian besar subyek penelitian mengalami nyeri ringan $(60 \%)$.

Perbedaan intensitas nyeri haid sebelum dan sesudah dilakukan senam haid diuji menggunakan Wilcoxon test. Hasil uji dapat dilihat pada tabel 1, nilai Asym.sig 0,001 di mana $p$ value $(0,001)<0,05$, artinya ada pengaruh terhadap intensitas nyeri haid antara sebelum dan sesudah dilakukan senam haid 
Tabel 2 Intensitas nyeri haid sebelum dan setelah konsumsi kunyit asam

\begin{tabular}{|c|c|c|c|c|c|}
\hline \multirow{3}{*}{$\begin{array}{l}\text { Intensitas } \\
\text { nyeri haid }\end{array}$} & \multicolumn{4}{|c|}{ Konsumsi kunyit asam } & \multirow{3}{*}{$\begin{array}{c}\text { Asymp } \\
\text {. Sig }\end{array}$} \\
\hline & \multicolumn{2}{|c|}{ Sebelum } & \multicolumn{2}{|c|}{ Sesudah } & \\
\hline & $\mathrm{n}$ & $\%$ & $\mathrm{n}$ & $\%$ & \\
\hline Tidak nyeri & 0 & 0 & 5 & 16,7 & 0,001 \\
\hline Nyeri ringan & 7 & 23,3 & 18 & 60 & \\
\hline $\begin{array}{l}\text { Nyeri } \\
\text { sedang }\end{array}$ & 20 & 66,7 & 5 & 16,7 & \\
\hline Nyeri berat & 3 & 10 & 2 & 6,7 & \\
\hline $\begin{array}{l}\text { Nyeri sangat } \\
\text { berat }\end{array}$ & 0 & 0 & 0 & 0 & \\
\hline Total & 30 & 100 & 30 & 100 & \\
\hline
\end{tabular}

Berdasarkan tabel di atas dapat dilihat bahwa sebelum mengkonsumsi kunyit asam, sebagian besar subyek penelitian mengalami nyeri sedang $(66,7 \%)$ dan setelah mengkonsumsi kunyit asam, sebagian besar subyek penelitian mengalami nyeri ringan $(60 \%)$.

Perbedaan intensitas nyeri haid sebelum dan sesudah konsumsi kunyit asam diuji menggunakan Wilcoxon test. Hasil uji dapat dilihat pada tabel 2, nilai Asym.sig 0,001 di mana $p$ value $(0,001)<0,05$, artinya ada pengaruh terhadap intensitas nyeri haid antara sebelum dan sesudah konsumsi kunyit asam..

Hasil uji Mann Whitney tentang perbedaan intensitas nyeri haid antara penatalaksanaan senam haid dan konsumsi kunyit asam pada subjek penelitian dapat dilihat pada tabel berikut ini

Tabel 3. Perbedaan antara senam haid dan konsumsi kunyit asam dalam mengurangi intensitas nyeri haid

\begin{tabular}{lllc}
\hline & Metode & N & $\begin{array}{c}\text { Asymp Sig. } \\
\text { (2-tailed) }\end{array}$ \\
\hline $\begin{array}{c}\text { Intensitas } \\
\text { nyeri }\end{array}$ & Senam haid & 30 & 0,405 \\
& $\begin{array}{l}\text { Konsumsi kunyit } \\
\text { asam } \\
\text { Total }\end{array}$ & 30 & \\
& 60 & \\
\hline
\end{tabular}

Dari tabel tersebut bisa dilihat nilai Asym.sig yaitu 0,405 di mana $p$ value $(0,405)>0,05$, artinya tidak ada perbedaan intensitas nyeri haid (dismenore) antara penatalaksanaan senam haid dan konsumsi kunyit asam

Hasil penelitian ini diperkuat oleh teori yang mengatakan bahwa senam dapat mengurangi nyeri haid, karena dengan melakukan olah raga atau senam dapat menghasilkan hormon endorphin yang berfungsi sebagai obat penenang alami yang dapat menimbulkan rasa nyaman (Puji, 2010).

Hasil penelitian mengenai intervensi senam ini juga sesuai dengan penelitian yang dilakukan oleh Novia (2008), tentang hubungan nyeri haid dengan olahraga pada remaja usia 16-18 tahun di SMA St. Thomas 1 Medan, didapatkan hasil ada hubungan kebiasaan olah raga terhadap penurunan tingkat nyeri nyeri haid $(\mathrm{p}<0,05)$. 
Berkaitan dengan kunyit asam, minuman herbal ini sudah banyak dikonsumsi oleh masyarakat luas. Gabungan dua komponen antara rimpang kunyit dan buah asam yang menghasilkan minuman kunyit asam, mengandung berbagai bahan aktif alami yang dapat menurunkan aktivitas enzim siklooksigenasi (COX). Oleh karena itu, minuman ini sering digunakan untuk mengurangi nyeri haid

Hasil penelitian ini sesuai dengan penelitian Marlina (2012) pada siswi di SMAN 1 Tanjung Mutiara yang menunjukkan bahwa setelah mengkonsumsi kunyit asam, sebagian besar siswi $(60,7 \%)$ mengalami perubahan intensitas nyeri, dari nyeri berat menjadi nyeri sedang, dan 39,3\% siswi mengalami perubahan intensitas nyeri dari nyeri sedang menjadi nyeri ringan. Hasil analisisnya juga menunjukkan pengaruh konsumsi kunyit asam terhadap penurunan intensitas nyeri haid $(\mathrm{p}<0.05)$

Faktor yang mempengaruhi respon terhadap nyeri dan nyeri haid misalnya usia, faktor psikologis dan ansietas sudah dikendalikan. Rentang umur subjek penelitian dalam penelitian ini adalah 17-20 tahun. Mengenai faktor psikologis dan ansietas, karena subjek penelitian dalam rentang umur yang sama dan dalam aktivitas akademis yang sama, maka rata-rata keadaan psikisnya juga hampir sama.

Selain itu, respon awal terhadap nyeri sebelum diberi perlakuan pada kedua kelompok intervensi juga rata-rata hampir sama, yaitu mengalami nyeri sedang. Setelah diberi intervensi, hasil pada kedua kelompok intervensi juga hampir sama, yaitu sebagian besar ada perubahan dari nyeri sedang menjadi nyeri ringan. Beberapa penelitian terkait juga sudah membuktikan, bahwa kedua intervensi, senam haid dan konsumsi kunyit asam efektif untuk mengurangi atau menurunkan nyeri haid sehingga kedua kelompok intervensi sama-sama baik dan tidak ada perbedaan antara keduanya dalam mengurangi nyeri haid

\section{SIMPULAN DAN SARAN}

\section{Simpulan}

Kesimpulan dari penelitian ini adalah bahwa senam haid $(\mathrm{p}<0,001)$ dan konsumsi kunyit asam( $\mathrm{p}<0,001)$ menunjukkan efektivitas yang secara statistik signifikan untuk mengurangi intensitas nyeri haid.

Implikasi praktis dari temuan penelitian ini, baik senam haid dan konsumsi kunyit asam dapat digunakan untuk mengurangi intensitas nyeri haid pada perempuan, dengan efektivitas yang sebanding.

\section{Saran}

Bagi perempuan yang mengalami nyeri haid agar dapat memanfaatkan metode senam haid dan konsumsi kunyit asam untuk mengurangi nyeri haid (dismenore) sebagai alternatif cara non farmakologi yang aman dan mudah untuk dilakukan. Bagi penelitian selanjutnya bisa membandingkan metode penatalaksanaan nyeri haid secara non farmakologi yang belum dilakukan dalam penelitian ini, bisa dilaksanakan dalam waktu yang lebih lama, dan dengan subyek penelitian yang lebih banyak. 


\section{DAFTAR PUSTAKA}

Al-jefout, M., Fraijeh, S.A, Hijazee, J., Al Qaisi, R., and Luskomb, G., 2014. Dysmenorrhea: Prevalence \& Impact on Quality of Life among Young Adult Jordanian Females, Elsevier Ltd. Journal of Pediatric and Adolescent Gynecology Available at : http://dx.doi.org/10.1016/j.jpag.2014.07.005. (12 Oktober 2014)

Alphatino, 2009. Pengaruh Pemberian Tehnik Nafas Dalam dan Terapi Musik terhadap Penurunan Intensitas Nyeri (Dismenore) pada Remaja Putri. Skripsi: Undiksha

Andika, V. 2010. Pengaruh Hipnoterapi terhadap Intensitas Nyeri Dismenore Pada Mahasiswa Prodi D III Kebidanan Semarang Poltekkes Kemenkes Semarang Tahun 2010. Skripsi. Semarang: Poltekkes Kemenkes Semarang

Anindita, A.Y. 2010. Pengaruh Kebiasaan Mengkonsumsi Minuman Kunyit Asam Terhadap Keluhan Dismenore Primer pada Remaja Putri Di Kotamadya Surakarta. Skripsi. Surakarta: UNS.

Anurogo, D.and Wulandari, A. 2011. Mengatasi Nyeri Haid. Yogyakarta: Penerbit Andi

Aziato, L., Dedey, F., and Lamptey, JC., 2014. Dysmenorrhea management and coping among students in Ghana: A qualitative exploration. Journal of Pediatric and Adolescent Gynecology. Available at http://dx.doi.org/10.1016/j.jpag.2014.07.002. (12 Oktober 2014)

Baziad, A. 2008. Endokrinologi Ginekologi. Jakarta: Media Aesculapius Fakultas Kedokteran Universitas Indonesia

Bobak, Lowdermilk, and Jensen. 2005. Buku Ajar Keperawatan Maternitas. Jakarta: EGC.

Chantler, I., Mitchell, D. and Fuller, A., 2009. Diclofenac potassium attenuates dysmenorrhea and restores exercise performance in women with primary dysmenorrhea. The journal of pain: official journal of the American Pain Society, 10(2), pp.191-200. Available at http://www.ncbi.nlm.nih.gov/pubmed/19038583 (3 November 2014).

Laila. N.N. 2011. Buku Pintar Menstruasi dan Solusi Mengatasi Segala Keluhannya. Jogjakarta: Bukubiru..

Marliana, M.T. 2014. Pengaruh Yoga Terhadap Tingkat Dysmenorhea pada Mahasiswi Tingkat I DIII Kebidanan STIKes Kuningan. Tesis. Semarang: Universitas Diponegoro

Marlina, E. 2012. Pengaruh Minuman Kunyit Terhadap Tingkat Nyeri Dismenore Primer Pada Remaja Putri Di SMA Negeri 1 Tanjung Mutiara Kabupaten Agam. Aceh: Universitas Andalas

Nair M.G., Wang H., Dewitt D.L., Krempin D.W., Mody D.K., Qian Y., Groh D.G., Davies A.J., Murray M.A., Dykhouse R. and Lemay M. 2004. Journal of: Dietary Food Supplement Containing Natural Cyclooxigenase Inhibitorss and Metods for Inhibiting Pain and Inflammation. Vol 06. United States

Novia, I. and Puspitasari, N. 2008.. Faktor risiko yang mempengaruhi kejadian dismenore primer. The Indonesian Journal of Public Health, Vol. 4, No. 2, 96-104. 
Oktaviana, A and Imron, R., 2012. Menurunkan nyeri dismenorea dengan kompres hangat. Jurnal Keperawatan , volume VIII(2), pp.137-141..

Ortiz, M.I., 2010. European Journal of Obstetrics dan Gynecology and Reproductive Biology Primary dysmenorrhea among Mexican university students : prevalence, impact and treatment. European Journal of Obstetrics and Gynecology, 152(1), pp.73-77. Available at http://dx.doi.org/10.1016/j.ejogrb.2010.04.015.

Ping, L. and Ming, E., 2010. International Journal of Gynecology and Obstetrics Dysmenorrhea in a multiethnic population of adolescent Asian girls. International Journal of Gynecology and Obstetrics, 108(2), pp.139-142. Available at : http://dx.doi.org/10.1016/j.ijgo.2009.09.018.

Proverawati, A dan Maisaroh,S.(2009). Menarche Menstruasi Pertama Penuh Makna. Yogyakarta:Nuha Medika

Prasetyo, S. 2010. Konsep dan Proses Keperawatan Nyeri. Graha Ilmu. Yogyakarta

Price, S. A and Wilson, L.M. 2006. Patofisiologi: Konsep Klinis Proses-Proses Penyakit. Jakarta : EGC

Puji, I. 2010. Efektifitas Senam Dismenore dalam Mengurangi Dismenore pada Remaja Putri di SMAN 5 Semarang. Skripsi. Semarang: Undip

Said, A. 2007. Khasiat dan Manfaat Kunyit. Jakarta: Sinar Wadja Lestari

Saktiyono. (2006). IPA Biologi 2. Jakarta:Erlangga

Seven, M. and Eski, F., 2014. Original Article Evaluating Dysmenorrhea in a Sample of Turkish Nursing Students. , 15(3), pp.664-671.

Tamsuri, A. 2007. Konsep dan penatalaksanaan nyeri. Jakarta : EGC

Thaina P., Tungcharoen P., Wongnawa M., Reanmongkol W. and Subhadhirasakul S. 2009. Uterine relaxant effects of Curcuma aeruginosa Roxb. rhizome extracts. Journal of Ethnopharmacology. 121: 433-43.

Wieser F., Cohen M., Gaeddert A., Yu J., Burks-Wicks C., Berga S.L. and Taylor R.N. 2007. Evolution of medical treatment for endometriosis: back to the roots?. Human Reproduction Update-Oxford Journals. 13 (5): 487-99.

Wiknjosastro, H. 2008. Ilmu Kandungan. Jakarta: YBP Sarwono Prawirohardjo Zannoni, L. Giorgi, L., Spagnolo, E., Montanari, G., Villa G., and Seracchioli, R. 2014. Original Study Dysmenorrhea, Absenteeism from School, and Symptoms Suspicious for Endometriosis in Adolescents. Journal of Pediatric and Adolescent Gynecology, 27(5), pp.258-265. Available at: http://dx.doi.org/10.1016/j.jpag.2013.11.008. 